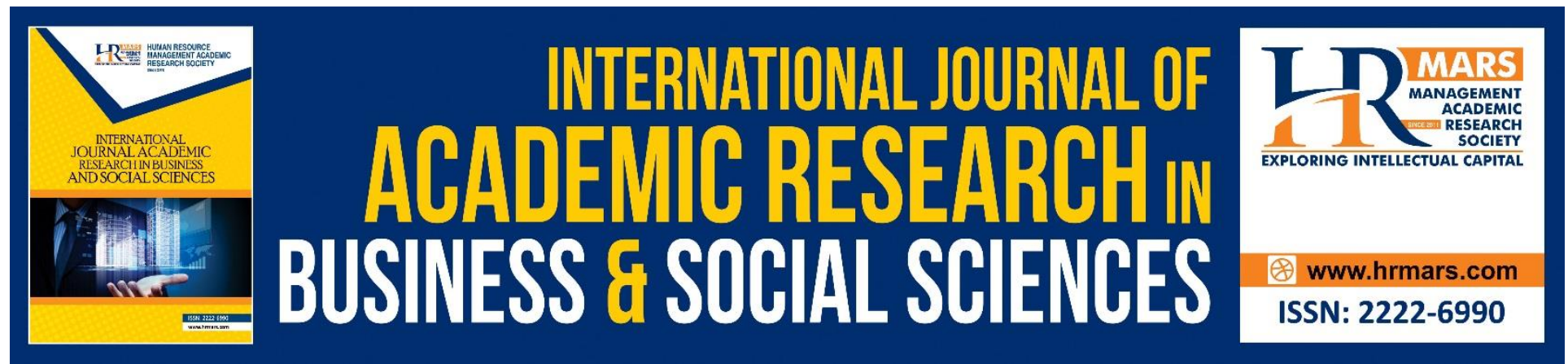

\title{
The Provenance of Stress among Employees in Government Hospital in Malaysia
}

\author{
Noorain Mohd Nordin, Munirah Mohamed, Nurul Azrin Ariffin, Nurhaslinda \\ Hashim, Nurul Azwa Ezzuren Zulkifli
}

To Link this Article: http://dx.doi.org/10.6007/IJARBSS/v10-i1/6804

DOI:10.6007/IJARBSS/v10-i1/6804

Received: 01 January 2020, Revised: 21 January 2020, Accepted: 30 January 2020

Published Online: 05 February 2020

In-Text Citation: (Nordin et al., 2020)

To Cite this Article: Nordin, N. M., Mohamed, M., Ariffin, N. A., Hashim, N., \& Zulkifli, N. A. E. (2020). The Provenance of Stress among Employees in Government Hospital in Malaysia. International Journal of Academic Research in Business and Social Sciences, 10(1), 33-45.

Copyright: (C) 2020 The Author(s)

Published by Human Resource Management Academic Research Society (www.hrmars.com)

This article is published under the Creative Commons Attribution (CC BY 4.0) license. Anyone may reproduce, distribute, translate and create derivative works of this article (for both commercial and non-commercial purposes), subject to full attribution to the original publication and authors. The full terms of this license may be seen

at: http://creativecommons.org/licences/by/4.0/legalcode

Vol. 10, No. 1, 2020, Pg. 33 - 45

http://hrmars.com/index.php/pages/detail/IJARBSS

JOURNAL HOMEPAGE

Full Terms \& Conditions of access and use can be found at http://hrmars.com/index.php/pages/detail/publication-ethics 


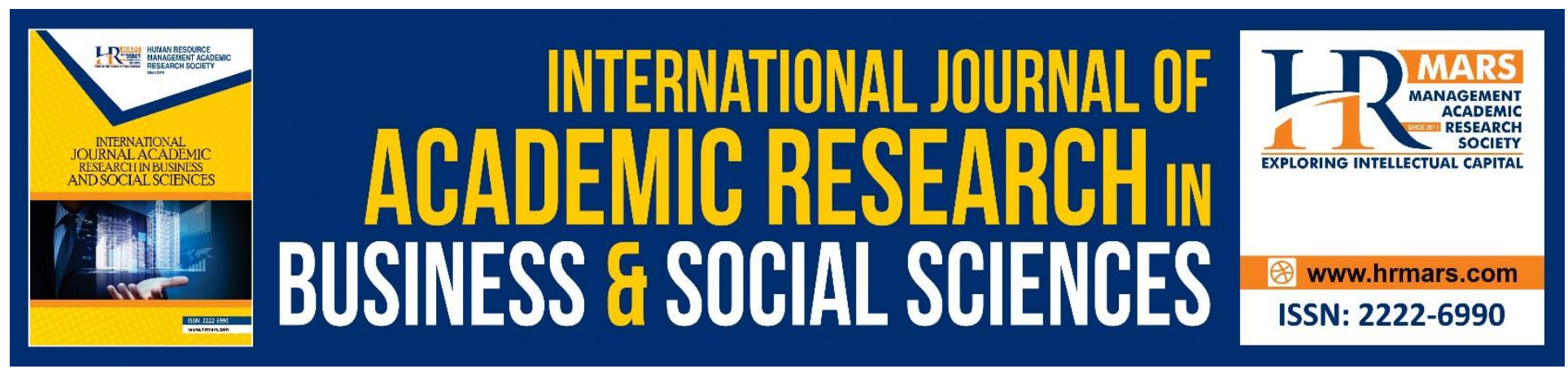

\title{
The Provenance of Stress among Employees in Government Hospital in Malaysia
}

\author{
Noorain Mohd Nordin, Munirah Mohamed, Nurul Azrin Ariffin, \\ Nurhaslinda Hashim, Nurul Azwa Ezzuren Zulkifli \\ Faculty of Business and Management, Universiti Teknologi MARA Melaka
}

\begin{abstract}
This study to identify the reasons for stress between employees in government hospital in Malaysia. The objective of this research is to measures the association between job enrichment, facilities and job satisfaction with provenance of stress and measure the predictor provenance of stress among employees in government hospital. Stress experienced at work can have adverse results for the prosperity of individual employees and association as entirety. This study is quantitative in nature and questionnaires distributed to gather information from respondents based on 150 sample size. The data obtained through questionnaires was analyzed and evaluated by statistical test correlation and regression. Most of the results show moderate and strong relationship on provenance of stress. Finally, limitation of study is also recognized and identified after the research is done. There are recommendations to the government hospitals and for future research to be conducted for better understanding in future.
\end{abstract}

Keywords: Stress, Job Enrichment, Facilities and Job Satisfaction.

\section{Introduction}

Stress at work was generally new wonder of contemporary lifestyles. The nature of work has experienced radical changes during the most recent time, and it is yet changing at hurricane speed. They have affected all professions, starting from a craftsman to a specialist, or a business pilot to a business official (Gianakos, 2000). According to Smith (2006), job stress signifies a risk to physical well-being. Work associated stress in the lifetime of specialists, subsequently, effects the strength of associations. A significant number of researchers have investigate business related anxiety yet over the most recent couple of decades, there has been significant increment in the pace of life with high increment of progress in the idea of many individuals and association(Tooren \& Jonge, 2010). Stress is presently known as worldwide phenomena and a tamed word extending from homes, families and associations. 
According to (Health and Safety Executive, 2013), some of the previous research concerns with the administration of stress among health care professionals. The investigations related include high turnover among medicinal services experts with high level of strain and stress and low levels of job satisfaction. They participate in physically requesting errands once a day and are frequently presented to people's needs, issues and sufferings. Stress lead to absenteeism, diminish job satisfaction and turnover. In health associations, work related anxiety is pervasive issue especially in emergency departments which human services suppliers manage extensive number of patients who have diverse conditions and they need to make a brisk determination and work proficiently which these contribute to stress (Kelly \& Cooper, 2015). Nursing is considered as a stressful occupation. Stress had an inference for well-being and the satisfaction level of the nurses included, which in the long run affects the value of care to the patients they attend. Study in nursing had distinguished plentiful stress relying upon the area of specialty. In any situation, some normal stress in these specialties incorporate poor employed connection amongst nurses and other colleagues, challenging correspondence and relationship with patient's relatives, crisis cases, high workload, understaffed and absence of help or contribution from their seniors (Price and Mueller, 1981). Another study finding (Vijayan, 2017) also showed a moderate level of occupational stress among nurses.

According to (Boamah \& Laschinger, 2016), various investigations determine job stress is by a wide margin the main source of stress for American grown-ups and that it has elevated vigorously over the previous couple of decades. Extended stages of job stress as assessed by the view of having slight control however heaps of desires had been exhibited to be related with increased rates of heart attack, hypertension and dissimilar issue. The National Health and Morbidity Survey (NHMS) directed by the Health Ministry a year ago revealed that the occurrence of emotional wellness issues was higher among more youthful grown-ups, those in the 16-19 age aggregate signified $34.7 \%$ and those in the $20-24$ age gather signified $32.1 \%$. The examination initiate that the pervasiveness of emotional well-being issues among individuals age 16 and above is $29.2 \%$. This is an engraved increase from a similar report done in 2006 , which announced a figure of $11.2 \%$. It furthermore uncovered a higher pervasiveness of psychological well-being topics among grown-ups from low household salary. By work, the prevalence was least among government and semi-government workers (Tan Sri Lee Lam Thye, 2013). (N. et al., 2015) showed the evident by recent research that high workload, lack of supervision and lack of support from higher authority are the main stressors among nurses.

According to Kahn, Wolfe, Quinn, \& Snoek (2014), job enrichment is an administration concept that includes upgrading occupations with the goal of more challenging to the employee and have less dreary effort. The motivation behind job enrichment is to make the position more fulfilling to the employee. Some of the employee will most likely be unable to rapidly adapt to their new obligations. Employees may feel over-burden and exhausted, so they may have a lower productivity rate. As a result, the employees had absence and heavier workload, some workers may not perform as productive as preceding employment improvement. These employees may really work better in a non-job-enriching environment. By not working out quite as well as 
wanted, they may feel awkward. Their poor performance may rapid lowers, which tends to negatively affect the employee's self-confidence and motivation (Hirokawa et al., 2012)

Work related anxiety is related with burnout, job satisfaction and physical in addition of emotional wellness results. Other than that, stress has severe consequences like frustration, high turnover and reduced productivity (Dagget et al., 2016). Stress addition to the practice of workrelated anxiety including poor supervision, conflict with companions and patients, high job requests and overtime are altogether associated with at least one measurements of burnout (Chan, 2003). Stress was perceived as an innate element of the work life of most professionals and growing evidence demonstrates that it might increase in seriousness. Work related anxiety had involved as a noteworthy contributing element to growing occupation disappointment, rapid turnover and high attrition rate among employees. Knezevic (2011) found that job stress does not just effect on the soundness of the individual yet in addition their capacity to adapt to work requests and this perpetually, truly hinders the viability of administration conveyance. There were no huge factual contrasts in apparent perceived job stress because of sexual orientation, age, and working department. However, there remained negative connection among the perceived job-related anxiety and the job satisfaction of the staff medical caretakers (Ross, 2005).

Many studies have been done determine the factors of stress but very few studies have been done and less evidence in the past studies conducting in government hospital in Malaysia. This research study drives to investigate and understand the factor that influences the provenance of stress. This is to show whether the existence of factors affect positively or negatively towards the targeted respondent. Currently, even though there are many studies on this topic, there is still very little research on it especially focusing on government hospital. Moreover, this study can provide significant information to the hospital, to act to their employees. Thus, the study intended to gauge the provenance of stress and assess the causes of job stress among government hospital staffs and investigate the connection between sources of job stress and independent variables.

\section{Literature Review}

\section{Provenance of Stress}

The work atmosphere is a vital provenance of the requirements and pressures initiating stress, basic and social resources to neutralize stress. The work environment issues that had been detected to relate to stress also well-being risks can be classified as those to do with the element of work and those to do with the social and hierarchical setting of work. Those that are intrinsic for the job include extend periods of time, work over-burden, time pressure, difficult or complex undertakings, lack of breaks, lack of assortment, and poor physical work conditions. For example, space, temperature and light(Mehta \& Singh, 2015).

Workplace stress grows from many causes. It can be a demanding manager, irritating collaborators, defiant students, angry clients, insecure conditions, long commutes and a constant workload. Work performance is additionally influenced by stressors, for case, family connections, finances and an absenteeism of rest stemming from fears and tensions about what's 
to come. Step by step instructions to deal with the influences of stress relies upon whether it is simpler to change the situation or change attitude toward it. With a specific end goal to amplify the return on investment associations are enabling representatives to work to their fullest potential (Finney et al, 2013).

Davis (2015) reported that positive connections between work stress and burnout are significant. Acknowledgment of a coordinated procedure of job stress and anxiety among medical caretakers is a fundamental advance to create effective management strategies for diminishing the issue of employment burnout and stress. Iranian research revealed that including Hebrani (2008) demonstrated that the most noteworthy power of stress among hospital medical caretakers is identified with stress making elements of administration and the slightest anxiety making factors is identified with interpersonal components. Besides, the average of tension between various parts of the doctor's facility was not essentially different. Cheung and Yip (2015) highlighted that work connections are possible stress. Two provenances of stress in this field are the conflicts with colleagues and the absence of staff support. Another evaluation demonstrated that absence of social help from associates and bosses and less satisfaction with the head Nurses contributed fundamentally to the presence of stress (Sveinsdottir,2006), while the Health and Safety Executive of United Kingdom distinguish the negative influence of absence of understanding and support since their administrators, on laborer's anxiety.

The developing awareness with the suggestions of work stress for medical attendants remains by the total number of studies exploring work related stress in nursing. Work related anxiety is a perceived issue in medicinal services specialists (Gholamzadeh et al., 2011). Nursing has been recognized as an occupation that has abnormal states of stress (Xianyu \& Lambert, 2006).Lately, studies about nursing have discovered that the causes and outcomes of work-related anxiety causes phenomenon are the outcome of an inequity between the individual and the workplace. The provenance of stress experienced by medical caretakers may contrast from nation to nation and from every individual or group of nurses, contingent upon the complex communication between their identity, qualities, abilities, and conditions (Gonge \& Buus, 2015).

A stressor definite as any request complete by within the inside or outside climate that fault a person's stability and for which reclamation is required. Additionally, work stress can be identified with working environment attributes that present a risk to people (Bridger et al., 2007) Such attributes may influence hierarchical act by falling productivity and competence that thusly hurt the association (Brown \& Uehara, 1999). Research led by Lamadah and Sayed (2014) about the difficulties confronting the nursing profession in Saudi Arabia claimed that many difficulties can cause stress, including poor working conditions, for example, gender, work-family strife, long working hours, high turnover rate, lower patient satisfaction and pivoting shifts.

\section{Job Enrichment}

Job enrichment is an administration knowledge that includes upgrading occupations, so they are more difficult to the worker and have less redundant work. The idea depends on (Herzberg \& Jason, 1968) expressed that the best worker inspirations, in view of a few examinations are accomplishment, acknowledgment, work itself, duty, headway and growth. To improve worker 
inspiration and productivity, occupations should to be altered to expand the motivators present for the employee.

As stated by Chandrasekhar (2011), work associated anxiety happens when needs and pressures does not coordinate representative's knowledge, dimensions and adapting abilities. Poor work conformation, work association and administration can add to psychosocial dangers to representatives that can prompt negative results, for example, work related anxiety burnout and dejection. Situations that can realize work environment stress include unreasonable workloads, absence of part lucidity or conflicting parts, work uncertainty, ineffectively oversaw association, absence of help from higher administration and ineffectual correspondence.

A few investigations concentrating on the health care services segment have demonstrated that employees are presented to an assortment of extreme work-related stress, for example, time weight, low social support at work, a high workload and vulnerability concerning patient treatment (SundinLisa et al., 2015) .In this sense, medicinal services workers are at a high danger of encountering extreme trouble, burnout and both mental and physical sickness. Thusly, this might influence doctor's facility results, for example, the nature of care gave by such organizations (Stansfeld \& Candy, 2006).

\section{Facilities}

A health facility was, by and large, any area where healthcare is provided. Health facilities extend from small clinics and offices to vital care centers and large hospitals with elaborate emergency rooms and trauma centers. The quantity and quality of health facilities in a nation or locale is one normal measure of that range's blooming and personal satisfaction. In numerous nations, health facilities are managed to some degree by act permitting by an administrative organization is regularly essential before an office may open for business. The workload of a health facility is frequently used to show its size. Large health facilities are those with a more noteworthy patient load (Ahmadi-Javid et al., 2017).

Most stressors can be found in the workplace and they may incorporate horrible working conditions, overwhelming workloads and authoritative issues, scarcity of assets, lack of support, lack of self-sufficiency, and lack of involvement of contribution in basic leadership. The work environment can likewise include physical stressors, for example, errand related commotion, swarming, the measure of the work place, security or youth brutality, and managerial weights such as bolster from administrators and role ambiguity (Brown and Uehara, 2008). Effective human resource management was connected to expanded hierarchical and worker execution (Armstrong, 2005). Arrangement of workers with the necessary facilities that they must play out their obligations and parts are progressively being a wellspring of quality for upgrading employee's execution. As indicated by Chandrasekhar (2011) employees can't work successfully without adequate work facilities. Moreover, employees burn through $50 \%$ of their lives inside the restriction of the inner condition of their work environments which profoundly impacts their mental status, activities, abilities and their performance. It takes that enhanced performance is assumed to be because of better facilities within the workplace environment. Davis (2015) contends that better workplace facilities will help the employee's effectiveness and enhance the organizations productivity. 
Past work had discovered a high prevalence of burnout among medical caretakers worldwide (Poghosyan, Clarke, Finlayson, and Aiken, 2010) and different components, including poor workplaces and low recruitment, had been accounted toward prompt burnout between nurses. For instance, nurses frequently work long sporadic hours, had high workload and work request and had awful encounters (Sundin, Hochwalder, Bilt, and Lisspers, 2015). Likewise, poor workplaces and low staffing challenge medical caretakers' capacity to bring care to the most noteworthy value, which may additionally expand stress and burnout (Sundin, 2015). Studies show that medical nurse burnout has negative impact not just for patient care and safety (Arnold, 2007), however can likewise influence the general association by diminishing the productivity of workers regarding expanded absenteeism, expanded turnover, and decreased in quality of administrations (Chandrasekhar, 2011). Then again, lessening medical attendant burnout has been found to positively affect patient care, for example, diminishing patient diseases by $30 \%$ (Cimiotti, Aiken, Sloane, \& Wu, 2012).

\section{Job Satisfaction}

Job satisfaction was accepted to be a key factor that impacts execution of people and associations. Dissatisfied work drive negatively affects execution of the offices. In addition, it is a pushing factor for movement of health laborers, both from provincial regions to the urban communities and out of the nation (Moustaka \& Constantinidis, 2010). Therefore, it was an important that imperative exertion of human resource administration in the health area to reinforce the motivation of health workers. Researchers had watched that dissatisfied workers, if stayed in the association, may include in counter-beneficial exercises, for example, burglary, poor administration, destructive rumors and sabotage of equipment. Representatives job dissatisfaction offers ascend to abnormal state of turnover intention which at last prompts laborer's turnover (Williams and Huber, 2013).

There were various interrelated elements that determine the level of job satisfaction of health work force. These incorporate unacceptable working conditions described by overwhelming workloads, absence of expert self-governance, poor supervision, long working hours, hazardous working environments, deficient aptitude structures, poor compensation, and poor access to essential supplies and constrained or no entering to capable advancement openings and inward and worldwide movement determine the motivation of health work force (Kahn, Wolfe, Quinn, and Snoek 2014).

Kahn, Wolfe, Quinn, and Snoek (2014) stated that job satisfaction was utilized to quantify how content a worker is through the job. High job satisfaction can enhance the eagerness of the staff and was advantageous to the achievement and development of the association. It can prompt lower turnover and high-quality administration. Healthcare staff with low job satisfaction might experience the medical complications of medicinal issues themselves and individual worker wellbeing may impact the general dependability of the healthcare staff. Disappointed employees were probably leave the association and accordingly, the rest of the workers may take part in counterproductive exercises for example, low-quality service and cause damage to equipment. 


\section{Research Methodology}

Data had collected from the sample using the validated and reliable research instrument. After the data had collected, they had analysed using correlation and multiple regression analysis. Correlation analysis was used to determine the relationship between the independent and dependent variables, while multiple linear regression analysis was used to determine the contributions of each of the significant predictors or independent variables towards the dependent variable.

Target populations of this study are the employees of the government hospital in Johor Bahru as the respective respondents. From this statement, 150 respondents have been chosen to represent the total population of the employees. For this research, the sampling method that will be use by researcher is convenience sampling under non-probability technique. The research instrument that has been use in this study is questionnaire. The questionnaires that has used in this research study will be classified into two section and other several parts.

First, Section A comprises the demographic background of the respondents. It consists of gender, age, marital status, nature of job and work shift of the respondents. Next, Section B is aimed to examine and evaluate the dependent variable and independent variable. The sources of the constructed instrument used on this research study were adopted from Scott 2013 for provenance of stress, while job enrichment (Lou, 2013), facilities (Kahn et al, 2014) and job satisfaction (Cousins, et al,2004) The data were analysed using the SPSS reliability and, the Cronbach's Alpha coefficient of reliability was derived. The reliability index Cronbach's Alpha of the instrument for provenance of stress was 0.623 while for independent variables which consist of job enrichment (0.669), facilities (0.780), and job satisfaction (0.717).

\section{Findings}

The study identified a relationship among the factors (job enrichment, facilities and job satisfaction) with the provenance of stress. In achieving this, Pearson $r$ correlation coefficients between each pair of variables had examined. As showed in Table 1, facilities ( $r=0.511)$, and job satisfaction ( $r=0.677)$ at the 0.5 level of significance were positively with moderate relationship with the provenance of stress. While job enrichment factor result showed $(r=0.712)$ with $(\rho=$ 0.000 ) which is less than 0.05 indicates that there was significance, and the R-value showed strong relationship. The findings from this research study point out that most of employees have positive provenance of stress. This is shown through the result where the independent variable of job enrichment, facilities and job satisfaction had significantly affected the dependent variable with provenance of stress. 
INTERNATIONAL JOURNAL OF ACADEMIC RESEARCH IN BUSINESS AND SOCIAL SCIENCES

Vol. 10, No. 1, Jan, 2020, E-ISSN: 2222-6990 ๔ 2020 HRMARS

Table 1: Pearson Correlation Coefficient between Job Enrichment, Facilities, Job Satisfaction with Provenance of Stress

\begin{tabular}{lcc} 
Variables & R-value & Result \\
\hline Job Enrichment & 0.712 & Strong Relationship \\
Facilities & 0.511 & Moderate Relationship \\
Job Satisfaction & 0.677 & Moderate Relationship \\
\hline
\end{tabular}

In relation to the question of what the best predictor for explaining provenance of stress, a multiple regressions analysis was conducted. Table 2 showed the results of regression analysis of the three independent variables which is job enrichment; facilities and job satisfaction regressed against dependent variable which is provenance of stress. Based on the table, the value for job enrichment is $(\beta=0.510)$ with $(\rho=0.000)$ which is less than 0.05 . While, the value for job satisfaction is $(\beta=0.410)$ with $(\rho=0.000)$ which also less than 0.05 . Thus, it indicates that there was significant relationship between job enrichment and job satisfaction with provenance of stress. Next, the value for facilities is $(\beta=-0.070)$ with $(\rho=0.338)$ which is more than 0.05 . Therefore, it indicated that there was no significant relationship between facilities and provenance of stress. Therefore, in this study showed that the job enrichment had the highest Beta-value and significant value that influence provenance of stress among employees in this government hospital.

Table 2: Regression Analysis Summary for Provenance of Stress

\begin{tabular}{lccc}
\hline Variables & Standardized Coefficient $(\boldsymbol{\beta})$ & Sig. & $\mathbf{R}^{\mathbf{2}}$ \\
\hline & & 0.000 & 0.605 \\
(Constant) & & & \\
Job Enrichment & 0.510 & 0.000 & \\
Facilities & -0.070 & 0.338 & \\
Job Satisfaction & 0.410 & 0.000 & \\
\hline
\end{tabular}

As shown in Table 2, the value of $\mathrm{R}^{2}=0.605$ this indicates that $60 \%$ of the variance in employee provenance of stress is influenced by independent variables of this study which are job enrichment, facilities and job satisfaction. Consequently, $40 \%$ of the variance in provenance of stress is explained by other factors. To conclude, job enrichment was the most significant predictor variable that contribute to the provenance of stress with the value of Beta Coefficient (0.510) or $51.0 \%$ and significant at 0.000 . Followed by job satisfaction with the Beta Coefficient $(0.410)$ or $41.0 \%$ and significant at 0.000 . But the only independent variable that shows a negative outcome in this research study is, facilities with the Beta Coefficient $(-0.070)$ and significant value 0.338 that showed not significant. This result was vice-versa with the previous study (Bradley, 2007) as their research outcomes showed a positive effect of facilities with the provenance of stress. 


\section{Conclusion}

Throughout this research study, it was found that there was a similar and differences in the results between the present study and the past one. The different outcomes can be resulted from so many reasons. One of the most obvious reasons was the different job nature and different sector that the research study took place. For instance, past research uncovered that there are many causes connected to work-stress. As indicated by a few researchers, reasons for workstress might be discovered both within worker personality and within the work environment (Newman, Beehr and Ratliff, 2011). It showed that, the different work environment might cause dissimilar way of thinking and actions of the targeted respondents.

A provenance of stress influences the successful growth of firms or organization. Hence, for the general hospital especially should act by knowing their employees' attitude and behavior is an important part to make the organization success. The results of this research illustrate that, having a high job enrichment was the main contribute to the provenance of stress. Therefore, it is suggested to the general hospital to implement more interesting wellness and entertainment programmed to the employees since its worth to be implemented. The employees may enjoy the programmed and release their tension and may prevent them from psychology or physically ill (Health and Safety Executive, 2013). Furthermore, it is suggested that management of the general hospital should improvise the communication and responds to feedback from the employees as it may reduce their burden which may lead to a better understanding that can reduce their job stress level.

The consequences of reward system play an important role to organization's service quality. Rewards bring motivation that may cause an employee stress level to decrease. Feeling motivated helps in efficiency and increase the performance of the organizations. There were many types of reward that can be implemented. For instance, reimbursements for education and free vacation for employees of the year. Thus, it is believed that this factor may reduce the stress level and increase company productivity (Kelsey, 2013).

The future researcher can further this study by selecting different independent variables to be tested in their future studies. As the results for $\mathrm{R}^{2}$ in this study was $60 \%$ which is the variance in employee's provenance of stress is influenced by independent variables. Hence, the future researcher may want to add other variables when conducting the research. Future researcher may investigate using other independent variables, for instance, incentives, work shift, environmental factors and work experience (Health and Safety Executive, 2013). Hence, it is recommended for future researcher to further the research into a different type of sectors or professions such as construction sector, education sector in order to extend the study in this field. This is because the cross study can bring out more reliable findings.

\section{Acknowledgement}

The author would like to thank the co-authors that have helped in conducting and completing this research. 
INTERNATIONAL JOURNAL OF ACADEMIC RESEARCH IN BUSINESS AND SOCIAL SCIENCES

Vol. 10, No. 1, Jan, 2020, E-ISSN: 2222-6990 ๔ 2020 HRMARS

\section{Corresponding Author}

Noorain Mohd Nordin, Universiti Teknologi Mara, Cawangan Melaka, Malaysia

Email: noorainnordin@uitm.edu.my

\section{References}

Ahmadi-Javid, A., Seyedi, P., \& Syam, S. S. (2017). A survey of healthcare facility location. In Computers and Operations Research. https://doi.org/10.1016/j.cor.2016.05.018

Armstrong, M. (2005). A Handbook of Human Resource Management Practice. Journal of Managing Human Resources Department, 80 (11), 300-378.

Arnold, B., Jari, H., Evangelia, D., \& Despoina, K. (2007). Job resources boost work engagement, particularly when job demands are high. Journal of Educational Psychology, 99 (2), 274284.

Boamah, S. A., \& Laschinger, H. (2016). The influence of areas of worklife fit and work-life interference on burnout and turnover intentions among new graduate nurses. Journal of Nursing Management. https://doi.org/10.1111/jonm.12318

Bridger, R. S., Kilminster, S., \& Slaven, G. (2007). Occupational stress and strain in the naval service: 1999 and 2004. Occupational Medicine. https://doi.org/10.1093/occmed/kql124

Brown, Z. A., \& Uehara, D. L. (1999). Coping with teacher stress: A research synthesis for Pacific educators. Pacific Resources for Education and Learning.

Chandrasekhar, K. (2011). Workplace environment and its impact on organizational performance in public sector organizations, Alagappa University, Karaikudi, India. International Journal of Enterprise Computing and Business Systems, 66 (1), 1-20.

Chan, D. W. (2003). Hardiness and its role in the stress-burnout relationship among prospective Chinese teachers in Hong Kong. Teaching and Teacher Education. https://doi.org/10.1016/S0742-051X(03)00023-4

Cheung, T., \& Yip, P. S. (2015). Depression, anxiety and symptoms of stress among Hong Kong nurses: A cross-sectional study. International Journal of Environmental Research and Public Health, 12 (9), 11072-11100.

Cimiotti, J., Aiken, L. H., Sloane, D. M., \& Wu, E. S. (2012). Nurse staffing, burnout, and health care-associated infection. American Journal of Infection Control, 40, 486-490.

Cousins, R., Mackay, C., Clarke, S., Kelly, C., Kelly, P., and McCaig, R. (2004). Management Standards and work-related stress in the UK: Practical development. Work and Stress: $a$ journal of work, health and organisation, 18(2), 130.

Dagget, T., Molla, A., \& Belachew, T. (2016). Job related stress among nurses working in Jimma Zone public hospitals, South West Ethiopia: A cross sectional study. BMC Nursing. https://doi.org/10.1186/s12912-016-0158-2

Davis, M., K. (2015). Intra role conflict and job satisfaction in psychiatric units. Journal of Nursing Research, 23 (6), 482-488.

Finney, C., Stergiopoulos, E., Hensel, J., Bonato, S., \& Dewa, C. S. (2013). Organizational stressors associated with job stress and burnout in correctional officers. Journal of BMC Public Health, 31 (3), 13:82. 
Gianakos. (2000). Burnout and perceived quality of care among German clinicians in surgery. International Journal Quality Health Care, 22, 525-30.

Gholamzadeh, S., Sharif, F., \& Rad, F. D. (2011). Sources of occupational stress and coping strategies among nurses who work in Admission and Emergency Departments of Hospitals related to Shiraz University of Medical Sciences. Iranian Journal of Nursing and Midwifery Research.

Gonge, H., \& Buus, N. (2015). Is it possible to strengthen psychiatric nursing staff's clinical supervision? RCT of a meta-supervision intervention. Journal of Advanced Nursing. https://doi.org/10.1111/jan.12569

Hebrani, P., Behdani, F., Motakabber, M. (2008). Examination of stressors among nurses. Journal of Fundamentals of Mental Health, (3), 237-231

Health and Safety Executive. (2013). Stress and Psychological Disorders in Great Britain 2013. Health and Safety Executive.

Herzberg, F., \& Jason, W. (1968). One more time: How do you motivate employees? Harvard Business Review.

Hirokawa, K., Taniguchi, T., Tsuchiya, M., \& Kawakami, N. (2012). Effects of a stress management program for hospital staffs on their coping strategies and interpersonal behaviors. Industrial Health. https://doi.org/10.2486/indhealth.MS1358

Kahn, Wolfe, Quinn, \& Snoek. (2014). Stress causing psychosomatic illness among nurses- Indian. Journal of Occupational and Environmental Medicine, 13 (1), 28-32.

Kelly \& Cooper. (2015). Occupational Stress amongst Nurses from Two Tertiary Care Hospitals in Delhi. Australasian Medical Journal AMJ, 3 (11), 731-738.

Knezevic, B., Milosevic, M., Golubic, R., Bolosevic, L., Russo A., Mustajbegovic, J. (2011). Workrelated stress and work ability among Croatian university hospital midwives. Journal of Midwifery, 27, 146-153.

Lamadah, S. M., \& Sayed, H. Y. (2014). Challenges Facing Nursing Profession in Saudi Arabia. Journal of Biology, Agriculture and Healthcare, 4(7): 20 -25.

Lou. (2013). The process of work stress: A dialogue between theory and research. Chinese Journal of Mental Health, 10 (9), 19-25.

Mehta, R. K., \& Singh, I. K. (2015). Stress among nurses working in critical care areas at a tertiary care teaching hospital, Nepal. Journal of Chitwan Medical College. https://doi.org/10.3126/jcmc.v4i4.11972

Michele Kelsey. (2013). A Company's Benefit System: How Rewards Affect Employee Behaviour. Journal of Employee Culture, 22 (4), 11-19.

Moustaka, L., \& Constantinidis, T. C. (2010). Sources and effects of work-related stress in nursing. Health Science Journal.

N, K. B. O. K. P., \& D, I. (2015). Work related stress, burnout, job satisfaction and general health of nurses. In International Journal of Environmental Research and Public Health.

Newman, J., \& Beehr, T. (2011). Personal and Organizational Strategies for Handling Job Stress: A Review of Research and Opinion. Journal of Personnel Psychology Spring, 44 (1), 211223. 
Poghosyan, L., Clarke, S. P., Finlayson, M., \& Aiken, L. H. (2010). Nurse burnout and quality of care: Cross-national investigation in six countries. Research in Nursing \& Health, 33, 288298.

Ross, G. F. (2005). Tourism Industry Employee Work stress: A Present and Future Crisis. Journal of Travel \& Tourism Marketing, 19 (2), 133-147.

Stansfeld, S., \& Candy, B. (2006). Psychosocial work environment and mental health - A metaanalytic review. Scandinavian Journal of Work, Environment and Health. https://doi.org/10.5271/sjweh.1050

Smith, T. (2006). Personality as risk and resilience in physical health. Journal of Current Directions in Psychological Science, 15 (4), 227-231.

SundinLisa, Iderc, H., Carina, B., \& Lisspersd, J. (2015). The relationship between different workrelated sources of social support and burnout among registered and assistant nurses. Psychologie Francaise. https://doi.org/10.1016/j.ijnurstu.2006.01.004

Sveinsdottir, H. (2006). Self -assessed quality of sleep, occupational health, working environment, illness experience and job satisfaction of female nurses working different combinations of shifts. Scandinavian Journal of Caring Services, 20 (2), 229-237.

Thye, T. S. L. L. (2013). Lee: Take stress in the workplace seriously. Borneo Post Online.

Tooren, V. D. M., \& Jonge, D. J. (2010). The role of matching job resources in different demanding situations at work: A vignette study. Journal of Occupational and Organizational Psychology. https://doi.org/10.1348/096317909X462257

Vijayan, M. (2017). Impact of Job Stress on Employees' Job Performance in Aavin, Coimbatore. Journal of Organisation \& Human Behaviour.

Xianyu, Y., \& Lambert, V. A. (2006). Investigation of the relationships among workplace stressors, ways of coping, and the mental health of Chinese head nurses. In Nursing and Health Sciences. 